Article

\title{
Smart Farming Techniques for Climate Change Adaptation in Cyprus
}

\author{
George Adamides ${ }^{1, * \mathbb{C}}$, Nikos Kalatzis ${ }^{2}$, Andreas Stylianou ${ }^{1} \mathbb{D}$, Nikolaos Marianos ${ }^{2}$, \\ Fotis Chatzipapadopoulos ${ }^{2}$, Marianthi Giannakopoulou ${ }^{1}$, George Papadavid ${ }^{1}$, \\ Vassilis Vassiliou ${ }^{1}$ and Damianos Neocleous ${ }^{1}$ (D) \\ 1 Agricultural Research Institute, P.O. Box 22016, 1516 Nicosia, Cyprus; a.stylianou@ari.gov.cy (A.S.); \\ marianthym@ari.gov.cy (M.G.); papadavid@ari.gov.cy (G.P.); vassilis@ari.gov.cy (V.V.); \\ d.neocleous@ari.gov.cy (D.N.) \\ 2 Neuropublic SA, 18545 Piraeus, Greece; n_kalatzis@neuropublic.gr (N.K.); n_marianos@neuropublic.gr (N.M.); \\ f_chatzipapadopoulos@neuropublic.gr (F.C.) \\ * Correspondence: gadamides@ari.gov.cy; Tel.: +357-22-403133
}

Received: 15 April 2020; Accepted: 25 May 2020; Published: 27 May 2020

check for updates

\begin{abstract}
Smart farming based on Internet of Things (IoT) technologies enables crop farmers to collect real-time data related to irrigation and plant protection processes, aiming to increase production volume, improve product quality, and predict diseases, while optimizing resources and farming processes. IoT devices can collect vast amounts of environmental, soil, and crop performance data, thus building time series data that can be analyzed to forecast and compute recommendations and deliver critical information to farmers in real time. In this sense, the added-value from the farmers' perspective is that such smart farming techniques have the potential to deliver a more sustainable agricultural production, based on a more precise and resource-efficient approach in the complex and versatile agricultural environment. The aim of this study is to investigate possible advantages of applying the Smart Farming as a Service (SFaaS) paradigm, aiming to support small-scale farmers, by taking over the technological investment burden and offering next generation farming advice through the combined utilization of heterogeneous information sources. The overall results of the pilot application demonstrate a potential reduction of up to $22 \%$ on total irrigation needs and important optimization opportunities on pesticides use efficiency. The current work offers opportunities for innovation targeting and climate change adaptation options (new agricultural technologies), and could help farmers to reduce their ecological footprint.
\end{abstract}

Keywords: smart farming; agriculture 4.0; Internet of Things; climate change; irrigation; sensors; potato; Cyprus

\section{Introduction}

In December 2019, the European Commission released a Communication entitled "The European Green Deal" stating its commitment for defining and implementing policies that will tackle climate and environmental-related challenges [1]. As it is denoted in this report, the atmosphere is warming and the climate is changing with each passing year while one million of the eight million species on the planet are at risk of being lost. The European Green Deal aims to respond on these challenges through the definition of a new growth strategy that will aim, among others, to protect, conserve, and enhance the European Unions' (EU) natural capital, and protect the health and well-being of citizens from environment-related 
risks and impacts. A key factor towards the realization of the European Green Deal is the promotion and investment in the necessary digital transformation tools that will facilitate the implementation of the required disruptive procedures and will act as the essential enablers of the envisioned changes. According to the Food and Agriculture Organization of the United Nations (FAO), water scarcity is one of the greatest challenges of the 21st century [2]. Agriculture accounts for an estimated $70 \%$ of global water withdrawals. In fact, water withdrawals are growing at almost twice the rate of the world population increase [3]. Taking into consideration that water resources are impacted by climate change [4] and an estimated 50\% surge in food demand due to population increase by 2050 [5], it is evident that, it is absolutely necessary for farmers to address water scarcity (i.e., the imbalance of water supply and demand), as well as water use efficiency [6-8].

Climate Smart Agriculture (CSA), aims to enhance the capacity of the agricultural systems to support food security [9]. CSA lies on three fundamental pillars: (i) better management of resources, (ii) improvement in conservation of ecosystem and landscape, and (iii) more adequate services for farmers to ensure the implementation of the necessary changes (e.g., smart farming technologies). Smart farming [10] and the Internet of Things (IoT) in agriculture [11], also called Agriculture 4.0, utilize advances in information and communication technology (ICT) to improve farm productivity, increase quality, yield, and profitability, while reducing the environmental footprint (i.e., efficient irrigation, precise use of pesticides, etc.). It is estimated that the smart agriculture market will grow by $12.7 \%$, annually [12]. Dorsemaine et al. [13] suggested the following definition for the IoT "a group of infrastructures interconnecting connected objects and allowing their management, data mining and the access to the data they generate." The application of IoT in agriculture aims at empowering farmers, providing decision tools and automation technologies that integrate products, knowledge, and services for increased productivity, quality improvement, and profit [14]. These technologies enhance the use of spatial data and real-time events (e.g., deployment of smart sensors in the field, scanning the field with drones) and are, currently, the driving force for the agricultural sector's sustainability $[10,15]$.

The domain of IoT technologies has evolved, not only scientifically [16], but also progressed since the initial hype some years ago and nowadays low-cost systems, such as accurate embedded sensors that measure the environmental context, are commercially available [11,17-19]. García et al. [20] provide an overview of the state of the art regarding IoT irrigation systems, and explain how IoT can enable farmers to collect real-time data related to irrigation and plant protection processes, so they can optimize irrigation and predict diseases to rationalize the use of plant protection products. By utilizing data stemming from IoT devices in the field, cloud computing, and analytics technologies, farmers are timely notified to proceed with such targeted activities. The result from synergized parameters such as air humidity, temperature, and other weather conditions is a service, which increases the total farm productivity, contributing to food security for an increasingly populated world. European farmers should be smart farming early adopters since they belong in one of the regions with the largest land devoted to agriculture in the world [21]. However, farmers and other agri-food stakeholders, usually are not aware of their existence or believe that they are too expensive, do not trust them yet, lack the (digital) skills to follow them, and most of them lack investment capability [22]. The last term refers to the farmers' and rest of agri-food stakeholders' organizational, business, and financial stamina to continuously engage, maintain, interact, and enhance their IoT expenditure. That said, Ferrández-Pastor et al. [23] and Elijah et al. [14] have identified several barriers that were delaying, thus far, these technologies' widespread development. These were expensive equipment, the difficulty in operation and their maintenance, and no standardization for sensor networks. Apart from the aforementioned barriers, Ojha et al. [24] added their portability (for easy application), energy-efficiency (for extended-lifetime), robust and fault-tolerant architecture (to ensure sustained operation), and interoperability between different components and communication technologies. 
Along the same line, Gangwar et al. [25] identified the following challenges in the deployment of ICT: social acceptance, reliability of acquired data, and technology deployment.

The Cypriot agricultural sector contributes around 2\% to Gross Domestic Product and $4 \%$ to labor force, while the value of raw agricultural products exported accounts for ca. $11 \%$ of the total domestic exports [26]. The most important crop products are potatoes, citrus, vegetables, and grapes, whereas meat (pork, beef, poultry, and sheep and goats) and milk (cow and sheep/goats) are the most significant livestock products consumed [27]. The small and fragmented farm holdings, the high input costs (e.g., pesticides, fertilizers, irrigation), the ageing and the low education level of farmers, the absence of skilled workforce, the land degradation and water scarcity, as well as various marketing problems, are only some of the several structural and chronic problems that the Cypriot agricultural sector has to deal with [28]. Small-scale farmers, viz. the vast majority of farmers in Cyprus, are particularly vulnerable to market and price volatility, while exhibiting low bargaining power and appearing unable to take advantage of economies of scale [27]. It is also projected that Cyprus will be highly affected by climate change impacts, such as increased temperature and decreased precipitation. These adverse effects might cause considerable loss in agricultural production and income [28,29]. Added to these challenges is the fact that the Cypriot agricultural sector still lags behind in terms of the adoption of new smart farming technologies and agriculture digitalization in general, which is a strategic goal of the next programming period (2021-2027). However, in the last years, Cyprus has introduced several initiatives to boost the sector, in areas such as modernization of farms, water and waste management, smart and resource-efficient farming, as well as environmental protection. Importantly, Cyprus is now focusing on the quality of agricultural products rather than quantity, taking advantage of its competitive advantages, e.g., the early cultivation/production of several crops, such as potatoes. The value of potato production in Cyprus accounts for ca. $14 \%$ of crop production, $6 \%$ of crop and livestock production, and $5 \%$ of the whole agricultural sector value (crop and livestock production, forestry, fishing, hunting, ancillary production). Furthermore, potato is the most important agricultural export product for Cyprus, representing ca. $40 \%$ of the value of raw agricultural products exported, however, potato is one of the two most water consuming crops in Cyprus (i.e., citrus and potatoes) due to the large agricultural areas they utilize [26]. Actually, based on the harvesting dates, the spring crop receives about $2641 \mathrm{~m}^{3} /$ ha/year and the winter crop twice as much.

Cyprus constitutes a rare example of a country where many measures are in place, specifically in agriculture, to increase the overall water use efficiency. Some of the measures successfully undertaken in Cyprus at the farmers' level include: (i) use of modern micro-irrigation systems, which practically cover $90 \%$ of the irrigated area in Cyprus, (ii) irrigation scheduling based on actual crop water requirement, and (iii) fertigation as a means to further increase yield per unit of water [30]. Nevertheless, recent studies by the Ministry of Agriculture, Rural Development and Environment of the Republic of Cyprus [31] and other research institutes [32-34], which refer to the climate change in agricultural terms in Cyprus, indicated that climate change is likely to increase irrigation water demands, reduce yields, and increase soil degradation. These studies have shown that there is highly variable nature of the climate in Cyprus, both in space and in time. Climate adaptation strategies in agriculture build on existing good management priorities, can increase water security and directly contribute to sustainable development [29]. Innovative technologies such as smart farming, are necessary for both adaptation to, and mitigation of, climate change. On this aspect, research in progress (smart farming techniques, telemetric stations, and soil sensors), in crop fields in Cyprus, aims to provide valuable insights applicable to the whole Mediterranean region [35]. One such example, is the Data-Driven Potato Production (IoT4Potato) of IOF2020 (https://www.iof2020.eu/trials/arable/data-driven-potato-farming [15]), which combines IoT with earth-surveying data, to help farmers reduce the production cost of potato and improve product quality, while at the same time reducing the environmental impact. 
The objectives of this article are twofold: (i) to present a methodological framework adapted to the southern Mediterranean region and small-scale farmers, focusing on Smart Farming as a Service (SFaaS), and (ii) present results from the deployment and operation phase of IoT smart sensors in a potato pilot study in Cyprus in the context of IoT4Potato. The scope of this study is to investigate potential advantages of applying the SFaaS paradigm, aiming to support small-scale farmers, by taking over the technological investment burden and offer next generation farming advice through the combined utilization of heterogeneous agro-environmental information sources. It is noted that in the case of this article, the exploration of such potential advantages does not include any advanced or other socioeconomic analyses, such as cost-benefit analysis. These issues, although being important in any research related to the adoption of new technologies by farmers, will be the subject of a future paper.

\section{Materials and Methods}

\subsection{Study Area}

Cyprus is the third largest island in the Mediterranean Sea, with a total area of $9251 \mathrm{~km}^{2}$. The territory under the control of the Republic of Cyprus covers an area of ca. $5760 \mathrm{~km}^{2}$ and comprises five main districts, namely Nicosia, Limassol, Larnaca, Paphos, and Famagusta. Potato is primarily and intensively cultivated in the Kokkinochoria area, Famagusta district. The area is situated in the southeastern part of Cyprus and

it is favored by fairly flat land, terra rossa (red) clay soils, and a favorable microclimate. The red soil of the area sticks to the tuber and is considered a unique characteristic of Cyprus potatoes in foreign markets. The climate of Kokkinochoria is semi-arid with mild, wet winters and long, warm and dry summers. The average annual temperature is estimated at $20.3^{\circ} \mathrm{C}$ and the average annual rainfall at around $300 \mathrm{~mm}$. Still, water shortage, the irrational use of synthetic/chemical fertilizers and pesticides, nitrate concentration, salinization of coastal aquifers due to over-pumping motivated by insufficient water supply and salinity of agricultural lands in the area, along with the increased production costs, put cultivation of potatoes at risk. It is noted, however, that the establishment of improved irrigation systems, dams, and irrigation networks in the area, as well as the application of integrated pest management principles by a large number of certified potato producers, are factors that maximize the benefits of applying smart farming in the potato (sub)sector [28].

\subsection{Methods of Production and Cropping System}

For the needs of the IoT4Potato project, a farm located in Liopetri village ( $35^{\circ} 0^{\prime} 34^{\prime \prime} \mathrm{N}, 33^{\circ} 53^{\prime} 34^{\prime \prime} \mathrm{E}$ ), Kokkinochoria area, was chosen as the first case study. The farm is headed and managed by a middle-aged male who agreed to provide a parcel of $0.5 \mathrm{ha}$, which was planted in rows with a winter potato crop (Spunta variety) on 23-24 September 2019. As it is described in detail in the following sections, on 24 September, agro-environmental sensing equipment was installed in the field necessary for the realization of the designed smart farming approach. A modern irrigation system consisting of 176 micro-sprinklers (flow $180 \mathrm{~L} / \mathrm{h}$ ) was used for irrigation purposes. Basal fertilization was applied on 23 September 2019, along with sowing (broadcasting at sowing) and top-dressing fertilization on 28 November 2019 through the irrigation system (fertigation). The plant diseases monitored were Phytophthora infestans (Late Blight) and Alternaria solani (Early Blight). It is worth mentioning that at the first contact, the farmer appeared reluctant to participate in the project. This hesitation stemmed from his perception that smart farming and new technologies in general, are not capable of providing short-term solutions, such as reducing the cost of production. As a result, he was not willing to take any "risk". In fact, risk-aversion is a characteristic of older and low-educated farmers in Cyprus. The farmer's perceptions are linked to the findings of Adamides et al. [22] who showed that elderly and low-educated farmers in Cyprus are less 
likely to adopt new (agricultural) technologies. Consequently, the farmers rely entirely on their practical experience and on traditional cultivation practices, leading, most of the times, to the irrational use of inputs, such as pesticides and fertilizers, as well as to the inefficient use of irrigation water. However, at the second contact, the farmer along with his young and highly-educated daughter, agreed to participate in the project.

\subsection{Smart Farming Approach}

The technological approach that was deployed and utilized for the realization of the "Data-Driven Potato Production" pilot was the gaiasense smart farming (SF) solution [36]. The gaiasense realizes the SFaaS paradigm aiming to support the farmers by taking over the technological investment burden and offer next generation farming advice through the combined utilization of heterogeneous information sources. Having under consideration the small and fragmented holdings of farmers in southeast Europe, gaiasense follows an innovative approach where the farmer(s) gets an annual subscription with a charging fee which is proportional to the area of their holdings and to the type of farming advisory services that they are subscribed (e.g., pest management, irrigation, and fertilization). The gaiasense SF approach was initiated in 2015 in Greece and until today is available to 26 different areas, in six EU countries, covering $>60,000$ ha and 17 different crops. However, and given the innovative approach of gaiasense, important outcomes are continuously under extraction and analysis with regard to the operational techno-economic requirements that will make viable the large-scale deployment of the SFaaS approach. One of the main requirements is that the areas where the gaiasense technological infrastructure is to be deployed should serve a high number of farmers, that are subscribed to the service or will potentially subscribe in the near future, in order to achieve economies of scale and become financially sustainable for the service provider who has the burden of the infrastructure costs. As it is illustrated in Figure 1, gaiasense consists of a set of information sources that include IoT-enabled agro-environmental sensing stations, Earth Observation services, farmer's digital calendar, and on-the-field observations of the cultivation.

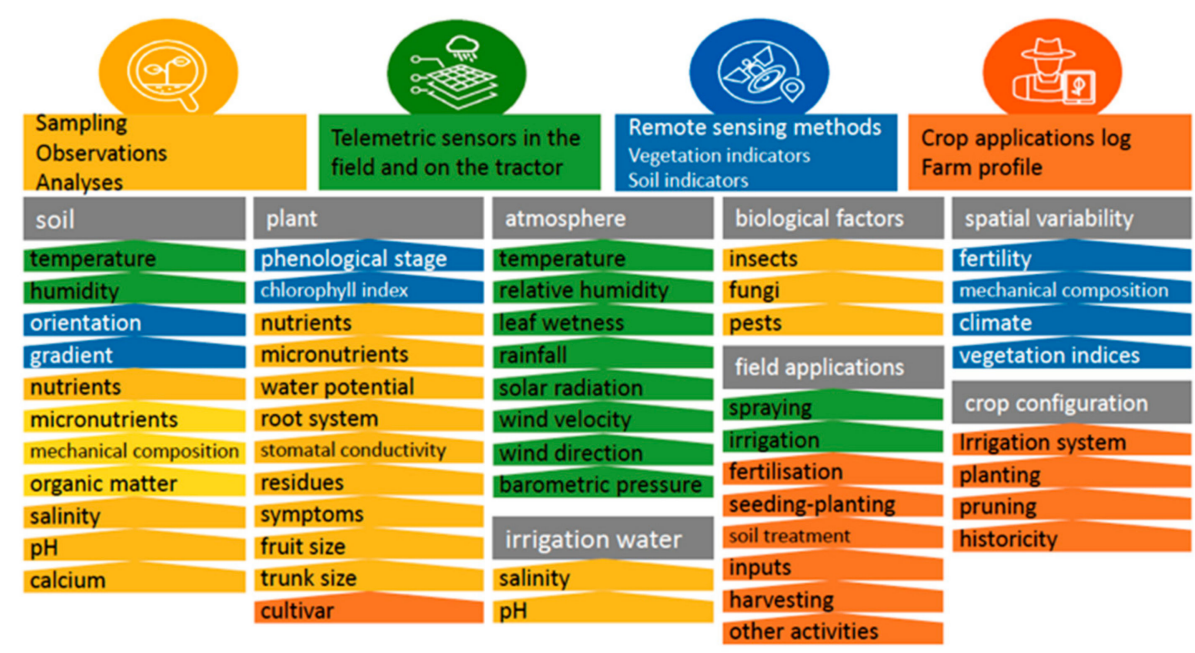

Figure 1. Information sources and measured data types towards the realization of smart farming.

The gaiasense system utilizes telemetric autonomous stations-called gaiatrons-which collect data from sensors installed in the field and record atmospheric, soil, and plant parameters (e.g., temperature, relative humidity, precipitation, atmospheric pressure, wind speed/direction, soil moisture, leaf temperature, humidity, and wetness) (see Supplementary File). The gaiatron station is an IoT 
"Deploy-and-Forget" platform, incorporating a wide variety of sensors intended for the continuous surveillance of cultivation environmental variables in selected agricultural areas. It is designed by NEUROPUBLIC (https://www.neuropublic.gr/en/), manufactured by qualified contractors and installed by specially trained company's personnel. Main communication of the gaiatron stations with the computer servers deployed in a cloud-computing environment is achieved through the utilization of either of the following protocols: GPRS/3G or UHF. It should be noted that these communication protocols (GPRS/3G) have been selected over more modern approaches (e.g., NB-IoT, Sigfox, LoRa) because of their service availability by telecom operators and coverage capabilities over the southeast Europe region. Throughout the Balkans and Cyprus, high geographical variability is demonstrated where mountainous areas and plains usually coexist in the same area, reducing the robustness and performance of other telecommunication protocols.

Data derived from Earth Observation (satellite) monitoring services, mainly Sentinel-1 and Sentinel-2 Copernicus missions, are also fused within the system. These satellite missions monitor variability in land surface conditions with a frequency of approximately 5 days. The gaiasense platform periodically searches for new Sentinel-2 imagery, downloads them, and performs the required processing for optical satellite images (i.e., atmospheric correction and cloud masking). As a result, the initial data are upgraded to higher-level products, such as NDVI (Normalized Difference Vegetation Index) or LAI (Leaf Area Index) indices that are automatically assigned to the agricultural parcels, allowing farmers and advisors to understand their crops growth and vitality.

The digital farmer's calendar contains the respective recording of the actions that the farmer/advisor performs at the field. The gaiasense offers the proper ICT tools and information system to record all information that is related to the daily cultivation work of the producer, such as fertilization application, plant protection, time, and duration of irrigation. This information provides the full and detailed picture of the exploitation, which contributes significantly to the decision-making process.

All the aforementioned data are collected to a central cloud computing repository where they are stored, processed, combined, and converted into facts based on advanced data analytic techniques (Figure 2). The outcomes of the processing are analyzed by experts (e.g., agronomists) in order to generate farming advice towards the optimization procedures of irrigation, pest management, and fertilization tailored to the context of the targeted parcel. The advice along with selected agro-environmental measurements are then mediated to the farmers through web-based applications. It should be noted that the role of the advisor/expert remains significant once the generated advice needs to be explained and the respective farmer's cultivation practices need to be supported and monitored. The necessary feedback, related to the actual farming practice that was applied as a response to the advice, is then returned to the gaiasense system (e.g., through the farmer's digital calendar) in order to further be analyzed and incorporated, supporting the generation of future advice.

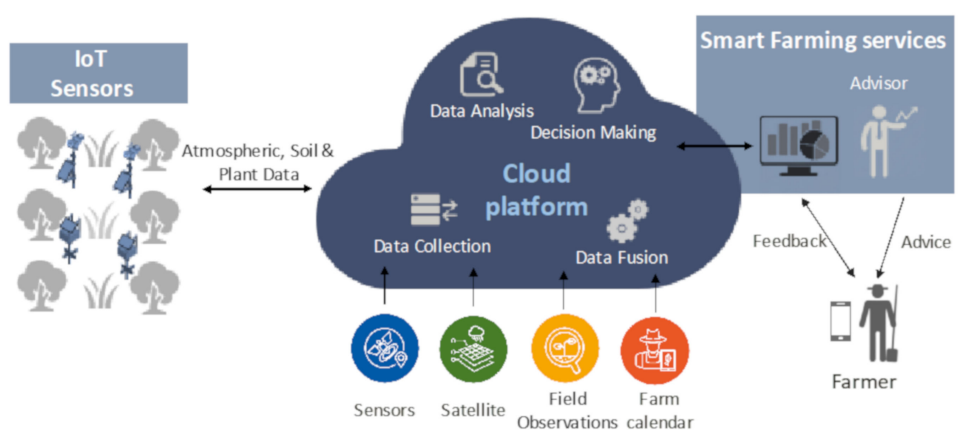

Figure 2. Information flow for the Smart Farming as a Service approach. 


\subsubsection{From Data Collection to Farming Advice}

The main objective when the gaiasense SF solution is about to be deployed at a new field is to develop and calibrate models supporting the generation of farming advice on pest management, irrigation, and fertilization to the context and needs of the parcels' soil-climate zone. To this end, the first action is to collect historic information related to the cultivar adjusted at the region, the cultivation conditions, and common practices and also the weather conditions existed at the candidate fields. Moreover, information concerning regular infestations from pest and diseases, the adjacent cultivations that could have hosted potential pathogens and pest enemies, etc., are completing the historic information of the pilot fields. The information is collected with the use of questionnaires that are completed by the administrative entity of each pilot site or through accessing open data repositories. The next step is the determination of soil and climatic zones and the selection of representative fields where the telemetric sensing stations will be installed. At this stage, the use of Earth Observation data from satellite missions are considered as a valuable tool [37]. The overall objective is that data monitored from the installed agro-environmental station is to be representative for the entire soil and climatic zone, aiming to avoid the installation of a large number of sensing equipment.

A reference/untreated field is necessary to be defined, where, in the first year, no chemical applications are performed in order for all the pest, disease, or other physiological agents to be recorded in their first appearance and also their biological evolution during the time to be monitored. All these data are important to the development of new scientific pest and disease infestation prediction models or adaption of already existing models to the microclimate conditions of the specific area. Regarding the rest of the pilot fields, during the first year, all the current agricultural practices are recorded and the fields are monitored regularly. In some cases, it is not feasible to have an untreated reference field, mainly because of the significant negative financial impact that an outbreak of a disease/pest could have on the selected productive farms. In order to overcome this issue, the first observation of an infestation occurring in the actual pilot field is recorded, followed immediately by the application of the appropriate pesticides.

In some cases, the necessary pest and irrigation management models are not developed from scratch. Based on the data collected during the first year, existing models are adapted according to the conditions of the pilot fields. As it is expected, this adaptation is more straightforward for cultivations that are demonstrating similarities, e.g., in terms of weather conditions.

The described process allows the development of a new or the calibration of an existing scientific algorithm/model that is then coded as software components. The models are fed with data from the aforementioned data sources (e.g., sensors), producing on a daily basis the respective outcomes that will be the core of the advice to be mediated to the farmer.

Pest management advice: Among the most important factors involved in defining potential risk infestations from insect pests enemies is temperature $\left(t^{\circ}\right)$, while for diseases, is the combination of temperature and relative humidity (RH\%). During their lifecycle, plants and insects require a specific amount of heat to develop from one stage to another. The accumulation of degree days that is required to complete the development of an organism is specific and countable [38]. With regard to potato crops, Early Blight (Alternaria solani) and Late Blight (Phytophthora infestans) are the two most dangerous diseases, that under favorable climatic conditions may cause total loss of the production [39]. Crop disease infection models are utilized as decision support systems in order to provide information on the probability of actual occurrence of the disease, periods of infection, and recommendations at the time of application of fungicides. However, these decision support systems need to be validated considering the particular conditions of the geographical area where potatoes are cultivated [40].

For the needs of the "Data-Driven Potato Production" pilot project, two infestation pressure models are developed aiming at addressing the risk of potato infestation by Early Blight and Late Blight diseases under 
Cyprus conditions. To this end, agro-climatic inputs, like temperature, leaf wetness, relative humidity, and precipitation are monitored along with observations including the plant's phenological stages and potential pest infestation indications that allow the adaptation of the pests growth presented in $[41,42]$ to the distinct properties of the pilot field.

The Early and Late Blight prediction models utilize as input the following variables: phenological stage, leaf-wetness duration, relative humidity at the leaf, and temperature at the leaf level. The predicted outcome ranges from 0 (when risk $=0$ ) to 100 (when risk $=$ the highest possible value) which is clustered to the following risk of infection classes: $R_{1}$-no risk, $R_{2}$-low risk, $R_{3}$-moderate risk, $R_{4}$ - high risk, $R_{5}$-very high risk.

During the model adaptation process, the calculated risk levels are cross-referenced with observations at the untreated reference fields in order to evaluate the correctness of the prediction and fine tune the constant parameters of the prediction model.

Irrigation advice: For a rational water management strategy to be effective, it should be based on direct and accurate determination of the optimal irrigation time and amount of irrigation. Determining the irrigation time is achieved by introducing critical water scarcity values derived from the time-gradient analysis of the soil moisture profile along the active root and hydrodynamic parameters of the plants. For this purpose, precise knowledge of the spatial distribution of the active bedrock is required in conjunction with the continuous recording of soil moisture. Irrigation management with soil water sensors (EnviroSCAN, Sentek Sensor Technologies), is based on maintaining soil water between upper limit (wetter value) and lower limit (drier value) - permitting unrestricted availability of water. The optimal irrigation dose is determined as the sum of daily water absorption values from the crop after the last irrigation. To this end, the gaiasense SF system utilizes soil moisture and soil salinity measurements at different depth levels. The measurements are fed to an algorithm that calculates—on a forecast basis—when the water reservoir will reach exceptional thresholds (minimum or maximum) [43].

For the initial development of the irrigation model to be utilized for the needs of the "Data-Driven Potato Production" pilot, the following data have been collected during the first cultivation period:

- Environmental conditions: Solar radiation, precipitation, relative humidity, wind speed, temperature, and soil moisture. Based on these data, it is feasible to calculate the amount of the plant's moisture loss due to the "evapotranspiration" phenomenon.

- Aquatic state of the plant: Leaf water potential and stomatal conductance that are recorded with the use of sophisticated equipment.

- Other parcel details: Irrigation system, planting distances, crop variety, mechanical soil composition, etc.

- Recordings of irrigation: Time and quantity of irrigation water utilized.

After the initial development of the irrigation model and in order for the gaiasense system to be able to provide irrigation advice even for parcels without a soil sensor, only the following parameters are required as input:

- Amount of irrigation water provided to the parcel;

- Amount of precipitation at the parcel;

- Water loss due to evaporation.

The output of the model is based on the calculated balance among the water inputs and losses and reflects the aquatic condition of the plants. This equilibrium is utilized by the experts in order to recommend the time and the dose of irrigation.

Two adaptations of the same irrigations model are under development for the cultivation of potato at Cyprus pilot fields. Given that in Cyprus there are two main cultivation periods, namely spring crop and 
winter crop, the two irrigation models are being developed considering the different needs of the plants on each season.

\subsubsection{Collected Field Data}

On 24 September 2019, agro-environmental equipment was installed at the pilot field (Figure 3). At the installation day, the installation team first met with the local experts (e.g., agronomists, producers/farmers) at the premises and the best possible plan for the deployment was set. In some cases, it is necessary to install the telemetric environmental sensing stations after the planting process is completed in order to avoid any disturbance due to heavy farming machinery utilized. One of the problems that the installation team faced was that at the pilot field, a wide solid bedrock existed under the depth of 45-50 cm which did not allow the installation of the soil sensor to the desired depth, allowing to measure soil properties (moisture and salinity) only at 10 to $40 \mathrm{~cm}$.

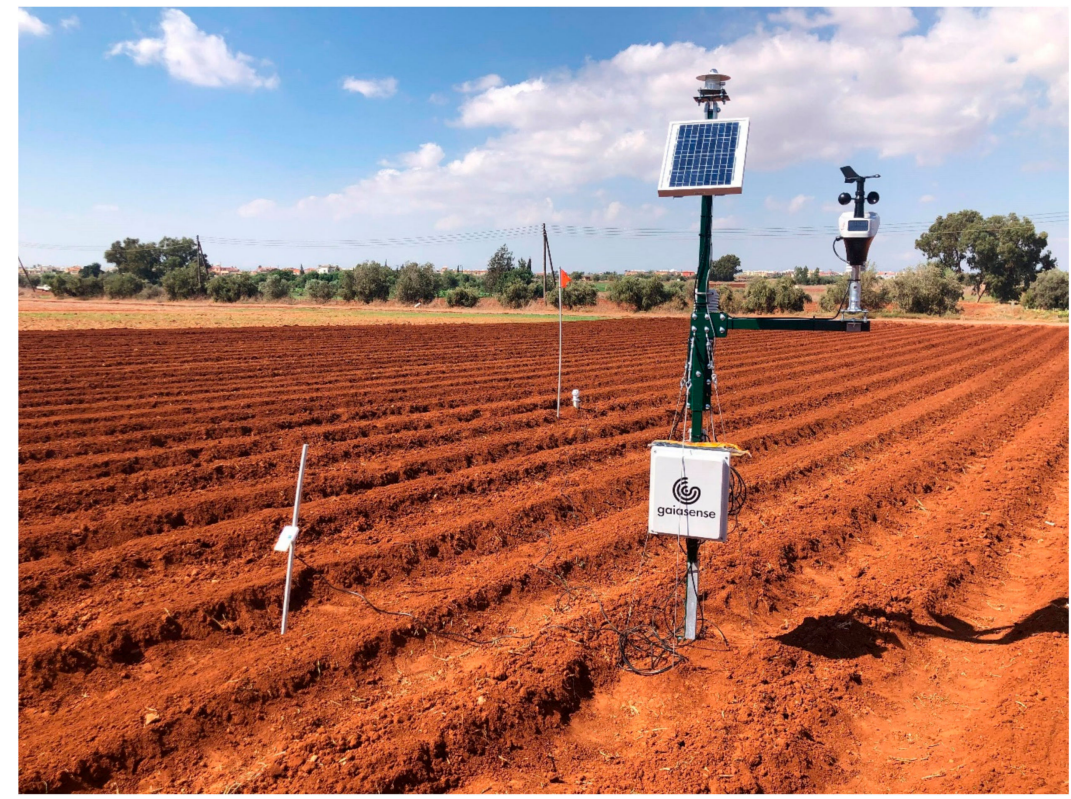

Figure 3. The installation of agro-environmental sensing equipment at the pilot field.

From the day of installation, specific parameters were continuously sensed, transferred, and stored to the cloud-based data repository. From 24 September 2019 until 1 February 2020, 3111 records of hourly recorded agro-environmental parameters of the following types were collected: date, air temperature, relative humidity, soil moisture (4 different depths), soil salinity (4 different depths), solar irradiation, atmospheric pressure, average wind speed, wind direction, precipitation, leaf temperature, leaf relative humidity, and leaf wetness. Soil parameters (moisture and salinity) are monitored through the Sentek's enviroSCAN probe (https://sentektechnologies.com/product-range/soildata-probes/), which was integrated with the sensing station. In addition, the performed cultivation practices (farm calendar) were also collected and integrated within the same data repository with the recorded agro-environmental parameters. Approximately 45 different calendar entries were recorded, including the following farming practices and observations: irrigation, fertilization, pesticides applications, crop's phenological stages, plowing, planting, and harvesting. As it was analyzed earlier in this article, among the core objectives during the first year of the deployment of the gaiasense SF solution to a new area is to gain the appropriate insights on the established farmer's practices and to adapt or develop 
models that will support the provision of farming advice. Based on this approach, the actual farming advice mechanism is expected to be operational on the winter crop of 2020. However, a first analysis of the collected data generated useful results that are presented in the following sections.

\subsubsection{Web-Based Application}

A web application was developed for the needs of the "Data-Driven Potato Production" pilot in order to support the mediation of the most important information to the end-users (farmers, advisors). Selected snapshots of the web application pages are illustrated in the following Figures 4 and 5.

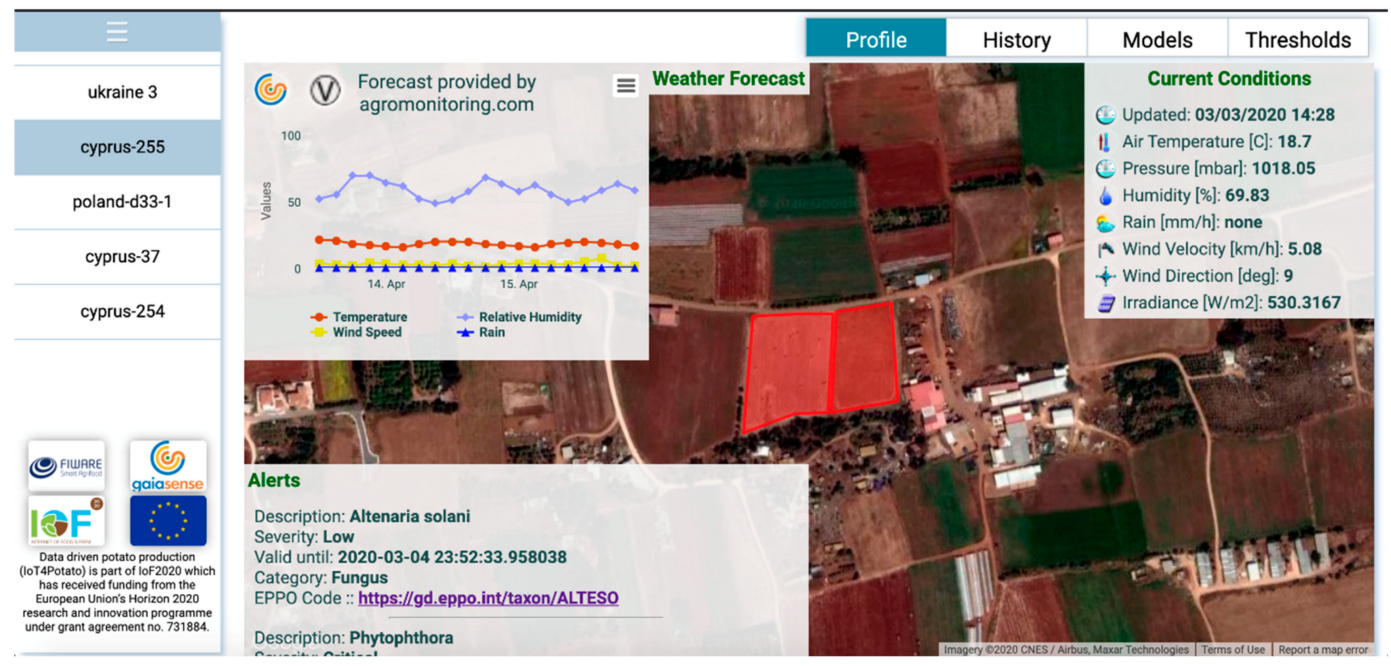

Figure 4. Current environmental conditions, active alerts, and weather forecast referring to the selected parcel.

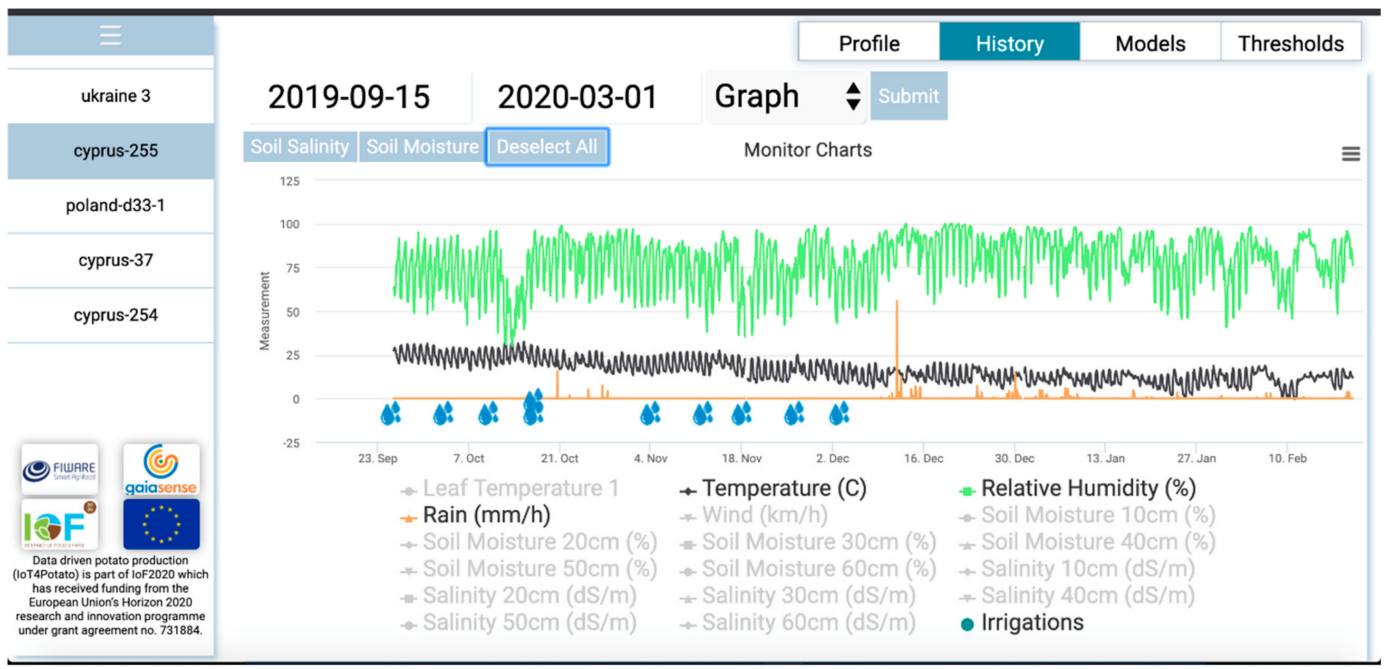

Figure 5. History of recorded agro-environmental measurements for the selected parcel are rendered to the user. 


\subsection{Expert Assessment Process}

The IoT4Potato/gaiasense SF solution was assessed by five experts (stakeholders/agronomists) involved in the IoT4Potato pilot study in Cyprus and with intimate knowledge of the area's agriculture. The number of experts is satisfactory considering the small agricultural sector of Kokkinochoria area. For this purpose, a questionnaire adapted from the IOF2020 project (Working Package 4) was used, which included four groups of questions: (a) usefulness of the solution (five questions), (b) ease of use (four questions), (c) application (four questions), and (d) three open-ended questions about the most important features of the solution, as well as the reasons for using and recommending it to farmers. For the closed-ended questions, a Likert scale ranging from strongly disagree to strongly agree was used. The goal of the questionnaire was to receive experts' feedback with regard to the overall experience with the gaiasense approach, and more particularly, with the installed IoT technologies and the developed IoT4Potato user interface for accessing the related information. The feedback received by stakeholders was taken into consideration for improving the product/solution. The new version will be reassessed in the future by experts, stakeholders, and end-users.

\section{Results and Discussion}

\subsection{Analysis of Collected Data on Irrigation}

The chart in Figure 6 illustrates recorded parameters related to the irrigation process at the pilot field.

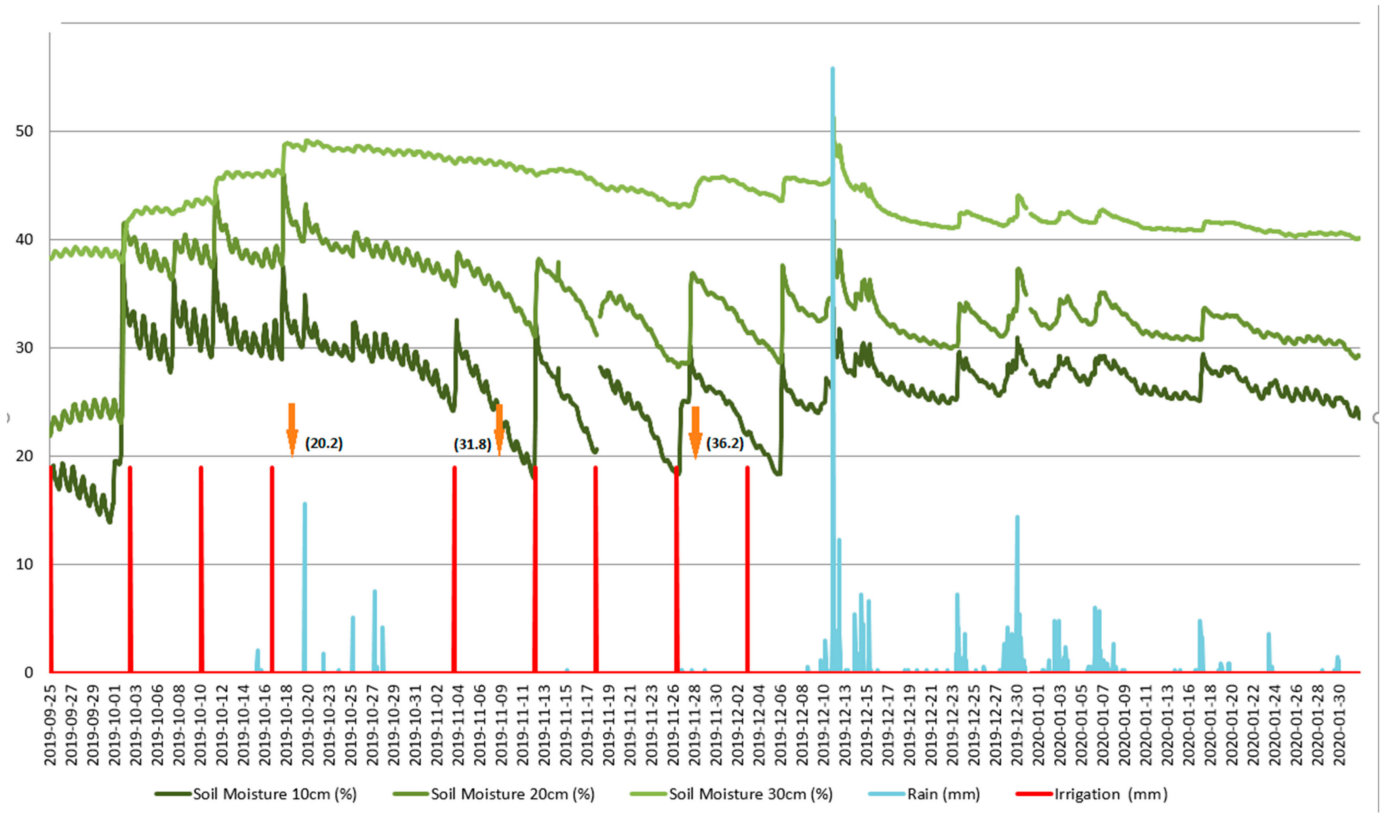

Figure 6. Recorded soil moisture in different depths combined with irrigation and rain events. Arrows imbedded in the figure show irrigation events $(\mathrm{mm})$ and amounts according to Food and Agriculture Organization of the United Nations CropWat tool.

One of the first observations is that at the surface layers $(10-30 \mathrm{~cm})$, the soil moisture decreases at a faster rate than in the deeper ones in which it remains almost constant and high. The deeper layers appear to be constantly saturated, a fact that is potentially related to the existence of the solid bedrock at these layers. In addition, all nine (9) irrigations where realized with the same irrigation dose, while the farmer could differentiate the dose depending on the phenological stage of the plants. For example, in the 
early stages of development as in the last ones, the water needs for the potato are lower than in the stages of tuberization and tuber growth. Data in Table S2 (Supplementary Materials) present the performed irrigations in combination with the observed phenological stage. The irrigation dose was set by the farmer on the concept of the total available soil water (Sa; $180 \mathrm{~mm} / \mathrm{m}$ soil depth), the fraction of available soil water permitting unrestricted evapotranspiration (p; 0.35), and the root depth (D; $0.30 \mathrm{~m})$ to calculate irrigation dose $(\mathrm{p} \times \mathrm{Sa} \times \mathrm{D} ; 18.9 \mathrm{~mm})$.

According to the collected soil moisture data, two irrigations (applied on 10/10/2019 and 17/10/2019) could have been avoided, viz. were in essence redundant. This provides evidence that ca. $37.8 \mathrm{~mm}$ irrigation water could be saved, corresponding to $22 \%$ reduction in irrigation water volume. In addition, irrigation performed on 26/11/2019 could be applied two or three days earlier as the soil moisture is recorded at relatively low levels. Another important observation is related with the recorded irrigation on $3 / 12 / 2019$. Although the farmer manually reports that the irrigation is performed on $3 / 12 / 2019$, the soil moisture recordings indicate an increase three days later, on 6/12/2019. Similar situations have also been observed in cases where the smart farming approach is in a development phase and the farmer's calendar reports are not always precise [44]. To evaluate adjustments of irrigation management following revision of soil moisture sensors lower and upper limits, site specific climatic data were used to estimate crop water requirements according to modified Penman-Monteith equation (FAO; [45]) using Cropwat supporting tool (http://www.fao.org/nr/water/infores_databases_cropwat.html). Results reinforce our findings for $22 \%$ more irrigation by the farmer at initial stages of growth (Figure 6), at which crop is considered less sensitive than at later stages of growth (i.e., tuber formation; [44]). Yet importantly, following root zone soil water movement during the period from 3/11/2019 to 3/12/2019, irrigation adjustments are also of major importance in order to avoid overwatering and large fluctuations in the upper portion of the root zone moisture, which can cause tuber cracks and eventually yield losses (https://www.yara.us/crop-nutrition/potato/agronomic-principles/) of growth [44]. However, the variation of microclimate even within the same area under recent climatic conditions is too high for the formulation of any systematic approach based on long-term climatic data of a wider area (e.g., FAO decision support system LocClim, http://www.fao.org/nr/climpag/pub/en0201_en.asp). In this context, it was previously suggested [46] that spatial and temporal variations in meteorological parameters and evapotranspiration, resulting from the microclimate of particular locations in Cyprus, necessitate a study for each of these locations separately. Thus, based on the collected data from the deployed volumetric soil water sensors irrigation, it is suggested to elevate soil moisture close to $40 \%$ at a depth of $30 \mathrm{~cm}$ mostly after formation of tubers or to maintain soil water at the upper soil layer within the two limits $20-40 \%$. The collection and visualization of such information through this practice on real time greatly assists the grower at the farm level on a more precise irrigation and enhanced irrigation efficiency, pointing towards a suitable adaptation approach.

\subsection{Analysis of Collected Data on Pest Management}

As it is already mentioned and for the needs of the IoT4Potato pilot project, during the first year of gaiasense SF solution deployment, agro-environmental data are collected from the pilot field along with plant observations in order to calibrate models for the daily automated estimation of Phytophthora infestants and Alternaria solani infestation pressure.

Figure 7 visualizes part of the monitored environmental parameters along with the calculated Phytophthora infestation risk. Based on this graph, there is an obvious relation of Phytophthora's calculated risk with increased precipitation, humidity, and temperature which is apparent on the time periods of 20-23/10/2019 and 12-24/12/2019. It is noted that the farmer mentioned that usually they do not face any problems with Phytophthora during the winter crop at the region that the field is located. However, according 
to the farmer's calendar Phytophthora infestations were visible on 23/12/2019. Farmer's observations are in-line with the outcomes of the Phytophthora infestation model as the calculated risk remains at maximum levels for the period 13-25/12/2019. The farmers performed two applications of pesticides on 24/12/2019 and 31/12/2019. According to the calculated infestation risk, the first pesticide application could have been applied earlier-on 16/12/2019-increasing the efficiency of Phytophthora prevention. The second pesticide application could have been avoided once the overall temperature was tending to be below $20^{\circ} \mathrm{C}$, hence, the overall infestation risk was also limited. In addition, infestation risk for Alternaria was calculated based on the recorded agro-environmental parameters. However, no Alternaria infestations were recorded and therefore no preventive pesticide applications were performed.

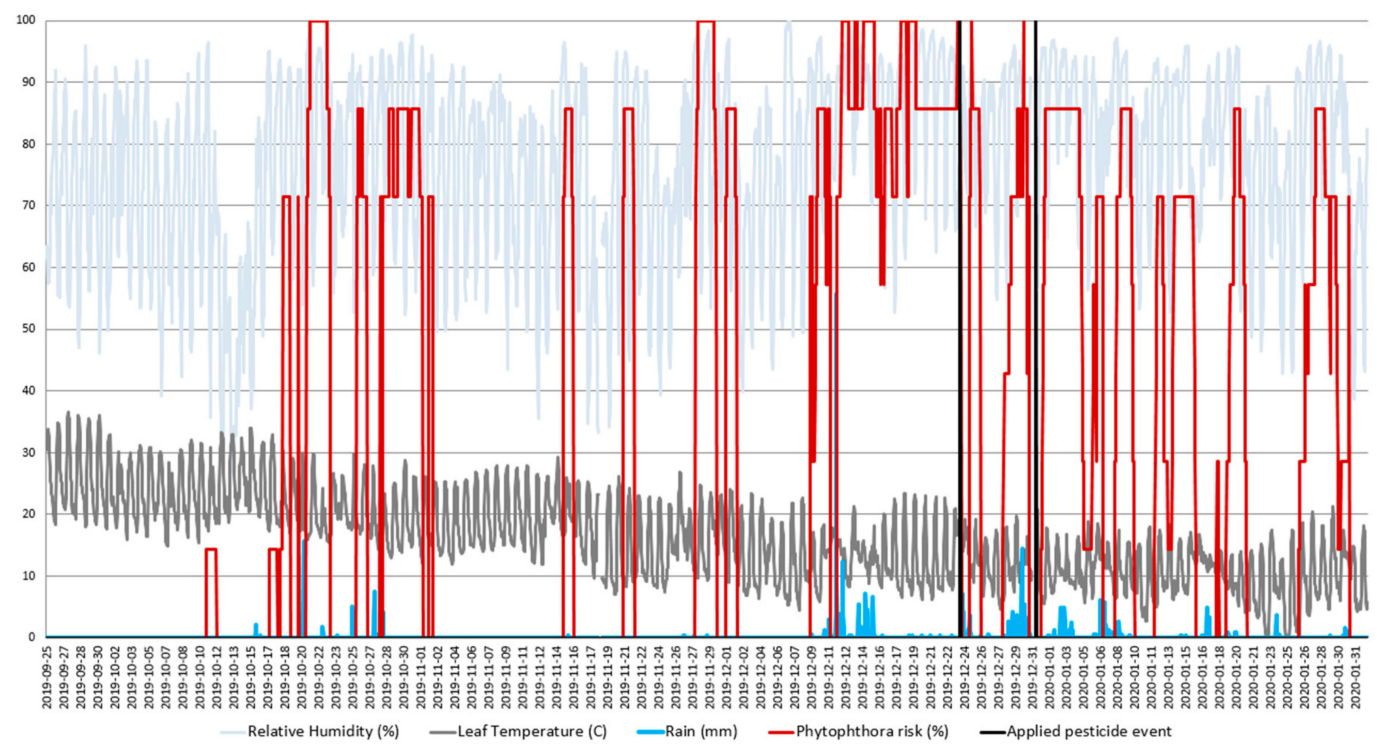

Figure 7. Recorded environmental variables and calculated risk of Phytophthora infestation.

\subsection{Expert Assessment}

Figure 8 illustrates the results from the experts' assessment of the gaiasense SF solution. Four stakeholders agree that it is clear that the proposed solution brings additional benefits to the farms, while three agree that it reduces the working time on the farm. In fact, discussions with the farmer-manager of the pilot farm revealed that some night visits to empirically observe the intensity of humidity in the field were avoided due to the information provided by the product/solution. Four participants agree that this solution makes decision-making more accurate. Likewise, four out of five agree and one strongly agrees that the gaiasense service offers more benefits compared to their current practice. Finally, four agree and one strongly agrees that this solution contributes to realizing societal goals, such as making farming more environmentally friendly.

With regard to the ease of use of the gaiasense solution, all five stakeholders agree that the design of the system is easy to understand. Similarly, all agree that the workflow of the solution is logical and delivers the result with just a few clicks. Two of them agree that it is easy to install the system, while the one was neutral and the other two declared "not applicable", as they were not actively involved during installation. Similarly, two experts agree that the system requires special ICT expertise; two disagreed with this statement and one was neutral.

Four out of five participants agree that the gaiasense solution is reliable. Two agree that they feel confident about using this digital solution, while three gave a neutral response. Four participants agree 
and one strongly agrees that it was clear to them which data are being collected by the system and who has access on them. Finally, three participants strongly agree, one agrees, and one is neutral about the fact that with using the gaiasense product, the farmer does not lose the feeling of being in charge of his/her farm operation and that he/she retains his autonomy.

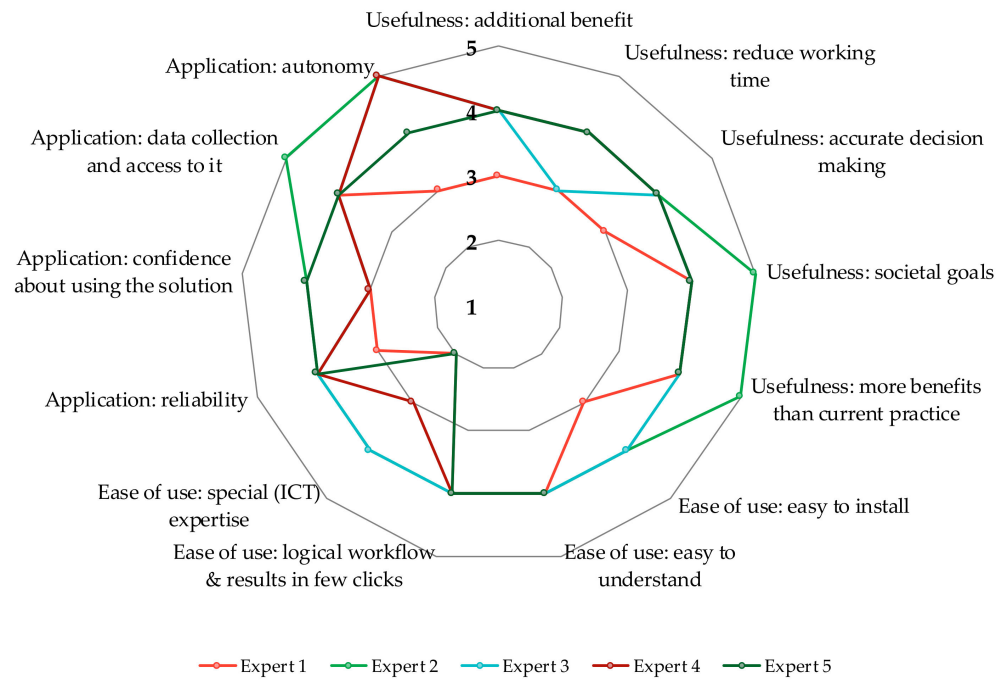

Figure 8. Responses of experts regarding the usefulness, ease of use and application of the smart farming solution. A 5-point Likert scale ranging from strongly disagree (1) to strongly agree (5) was used.

In an open-ended question, participants were asked to provide the most important features that they find beneficial to the farm when adopting the gaiasense solution. All five participants agreed on the following:

- Provision of real time on-farm data.

- Accurate information and fast access to information.

- $\quad$ Visual (graphs) and numerical (tables) integration of real time data.

They were also asked to provide the most important reasons for choosing to use this solution and recommending it to the farmers. The following reasons were recorded:

- The user can rely on timely and accurate information.

- The solution facilitates on-farm decision making.

- The solution is relatively user-friendly and provides several critical information that may help reduce costs and manage more effectively the farm. The solution seems to be a smart decision support system.

- Farmers might potentially increase their profits and at the same time protect the environment via the rational use of resources (e.g., irrigation, pesticides).

\section{Conclusions}

Cypriot farmers lag behind in terms of the adoption of smart farming technologies, while few attempts have been made by researchers to provide and document their benefits to the farmers. In this study, 
we present a methodological framework adapted to Mediterranean farming systems, focusing on smart farming as a service, as well as initial results from the deployment and operation phase of IoT smart sensors in a potato pilot study in Cyprus.

The results indicate a potential reduction of up to $22 \%$ on total irrigation needs and important optimization opportunities on pesticides use efficiency. Furthermore, as it is evident from the assessment process, the experts agreed on the usefulness, ease of use, and the reliability of the gaiasense solution. What is more, the experts identified the provision of real time and accurate data as well as the presentation of information with comprehensive tables and graphs, as the important features of the proposed smart farming system. We acknowledge, however, that the number of participants in the assessment process was relatively small and that future assessments should involve a larger number of experts, stakeholders, and end-users (especially farmers and agricultural extension officers).

The IoT4Potato is an on-going project, expected to be completed in December of 2020. Within the year 2020, two more pilot fields in Cyprus will be engaged and the respective installations of technological equipment will be realized. Engaging more farmers will support the extraction of additional results facilitating the identification of the best practices towards the large-scale realization of smart farming paradigm in Cyprus. Finally, the current work offers opportunities for innovation targeting and climate change adaptation options, and could help farmers to reduce their ecological footprint.

Supplementary Materials: The following are available online at http:/www.mdpi.com/2073-4433/11/6/557/s1, Table S1: Climatic and soil parameters i.e., relative humidity, precipitation, atmospheric pressure, wind speed/direction, soil moisture and leaf temperature and wetness recorded during the cropping period. Measurements were determined by gaiatron sensors. Hourly averaged data from 25/9/2019 to 5/10/2019 are presented. Table S2: Performed irrigations in combination with the observed phenological stage.

Author Contributions: Conceptualization, G.A., N.K., A.S. and D.N.; Investigation, G.A., N.K., A.S. and D.N.; Methodology, G.A., N.K., A.S. and D.N.; Project Administration, N.M.; Supervision, G.A., N.K., A.S., F.C. and D.N.; Writing—original draft, G.A., N.K., A.S., N.M., F.C., M.G., G.P. and D.N.; Writing-review \& editing, G.A., N.K., A.S., N.M., F.C., M.G., G.P., V.V. and D.N. All authors have read and agreed to the published version of the manuscript.

Funding: This work has been partially supported by the European Commission, Horizon 2020 Framework Program for research and innovation under grant agreement number 731884 .

Acknowledgments: The authors are grateful to the farmers, agronomists, experts, and other stakeholders involved in the pilot study.

Conflicts of Interest: The authors declare no conflict of interest.

\section{References}

1. EU. Communication from The Commission to The European Parliament, The European Council, The Council, The European Economic and Social Committee and the Committee of The Regions The European Green Deal. Available online: https://ec.europa.eu/info/sites/info/files/european-green-deal-communication_en.pdf (accessed on 2 April 2020).

2. FAO. The State of the World's Land and Water Resources for Food and Agriculture-Managing Systems at Risk; Earthscan, Ed.; Food and Agriculture Organization of the United Nations: London, UK, 2011.

3. WWAP. Water for a Sustainable World; UNESCO: Paris, France, 2015.

4. Piesse, M. Global Water Supply and Demand Trends Point Towards Rising Water Insecurity. Available online: http://www.futuredirections.org.au/publication/global-water-supply-and-demand-trendspoint-towards-rising-water-insecurity/ (accessed on 26 March 2020).

5. Alexandratos, N. World food and agriculture: Outlook for the medium and longer term. Proc. Natl. Acad. Sci. USA 1999, 96, 5908-5914. [CrossRef] [PubMed]

6. Hatfield, J.L.; Dold, C. Water-Use Efficiency: Advances and Challenges in a Changing Climate. Front. Plant Sci. 2019, 10. [CrossRef] [PubMed] 
7. Malheiro, M.T.; Pereira, R.M.S.; Gonçalves, A.M.; Pereira, P.A.S.; Caldeira, A.C.; Lopes, S.O. Hands on Experiments about Water Needs in Agriculture and Their Mathematical Modelling under Climate Change. In Proceedings of the 20193rd International Conference on E-Society, E-Education and E-Technology, Taipei, Taiwan, 15-17 August 2019; pp. 131-135.

8. Bashir, R.N.; Bajwa, I.S.; Shahid, M.M.A. Internet of Things (IoT) and Machine Learning based Leaching Requirements Estimation for Saline Soils. IEEE Internet Things J. 2019. [CrossRef]

9. Zecca, F. The Use of Internet of Things for the Sustainability of the Agricultural Sector: The Case of Climate Smart Agriculture. Int. J. Civ. Eng. Technol. 2019, 10, 494-501.

10. Walter, A.; Finger, R.; Huber, R.; Buchmann, N. Opinion: Smart farming is key to developing sustainable agriculture. Proc. Natl. Acad. Sci. USA 2017, 114, 6148-6150. [CrossRef]

11. Brewster, C.; Roussaki, I.; Kalatzis, N.; Doolin, K.; Ellis, K. IoT in agriculture: Designing a Europe-wide large-scale pilot. IEEE Commun. Mag. 2017, 55, 26-33. [CrossRef]

12. Chen, W.; Lin, Y.; Lin, Y.; Chen, R.; Liao, J.; Ng, F.; Chan, Y.; Liu, Y.; Wang, C.; Chiu, C.; et al. AgriTalk: IoT for Precision Soil Farming of Turmeric Cultivation. IEEE Internet Things J. 2019, 6, 5209-5223. [CrossRef]

13. Dorsemaine, B.; Gaulier, J.-P.; Wary, J.-P.; Kheir, N.; Urien, P. Internet of things: A definition \& taxonomy. In Proceedings of the 2015 9th International Conference on Next Generation Mobile Applications, Services and Technologies, Cambridge, UK, 9-11 September 2015; pp. 72-77.

14. Elijah, O.; Rahman, T.A.; Orikumhi, I.; Leow, C.Y.; Hindia, M.N. An overview of Internet of Things (IoT) and data analytics in agriculture: Benefits and challenges. IEEE Internet Things J. 2018, 5, 3758-3773. [CrossRef]

15. Villa-Henriksen, A.; Edwards, G.T.C.; Pesonen, L.A.; Green, O.; Sørensen, C.A.G. Internet of Things in arable farming: Implementation, applications, challenges and potential. Biosyst. Eng. 2020, 191, 60-84. [CrossRef]

16. Tzounis, A.; Katsoulas, N.; Bartzanas, T.; Kittas, C. Internet of Things in agriculture, recent advances and future challenges. Biosyst. Eng. 2017, 164, 31-48. [CrossRef]

17. Botta, A.; De Donato, W.; Persico, V.; Pescapé, A. Integration of cloud computing and internet of things: A survey. Future Gener. Comput. Syst. 2016, 56, 684-700. [CrossRef]

18. Rose, D.; Chilvers, J. Agriculture 4.0: Responsible innovation in an era of smart farming. Front. Sustain. Food Syst. 2018, 2, 87. [CrossRef]

19. Ramundo, L.; Taisch, M.; Terzi, S. State of the art of technology in the food sector value chain towards the IoT. In Proceedings of the 2016 IEEE 2nd International Forum on Research and Technologies for Society and Industry Leveraging a better tomorrow (RTSI), Bologna, Italy, 7-9 September 2016; pp. 1-6.

20. García, L.; Parra, L.; Jimenez, J.M.; Lloret, J.; Lorenz, P. IoT-Based Smart Irrigation Systems: An Overview on the Recent Trends on Sensors and IoT Systems for Irrigation in Precision Agriculture. Sensors 2020, $20,1042$. [CrossRef] [PubMed]

21. European Commission. Factsheet on 2014-2020 Rural Development Programme for Cyprus; European Commission: Brussels, Belgium, 2019; p. 7.

22. Adamides, G.; Stylianou, A.; Kosmas, P.C.; Apostolopoulos, C.D. Factors affecting PC and Internet usage by the rural population of Cyprus. Agric. Econ. Rev. 2013, 14, 16-36.

23. Ferrández-Pastor, F.; García-Chamizo, J.; Nieto-Hidalgo, M.; Mora-Pascual, J.; Mora-Martínez, J. Developing ubiquitous sensor network platform using internet of things: Application in precision agriculture. Sensors 2016, 16, 1141. [CrossRef] [PubMed]

24. Ojha, T.; Misra, S.; Raghuwanshi, N.S. Wireless sensor networks for agriculture: The state-of-the-art in practice and future challenges. Comput. Electron. Agric. 2015, 118, 66-84. [CrossRef]

25. Gangwar, D.S.; Tyagi, S.; Soni, S.K. A conceptual framework of agroecological resource management system for climate-smart agriculture. Int. J. Environ. Sci. Technol. 2019, 16, 4123-4132. [CrossRef]

26. CYStat. Agricultural Statistics 2015; Cyprus Statistical Service: Nicosia, Cyprus, 2017; p. 111.

27. Markou, M.; Stylianou, A.; Giannakopoulou, M.; Adamides, G. Identifying Business-to-Business Unfair Trading Practices in the Food Supply Chain: The case of Cyprus. New Medit 2020, 19, 19-34. [CrossRef] 
28. Stylianou, A.; Sdrali, D.; Apostolopoulos, C.D. Capturing the diversity of Mediterranean farming systems prior to their sustainability assessment: The case of Cyprus. Land Use Policy 2020, 96. [CrossRef]

29. Sofroniou, A.; Bishop, S. Water scarcity in Cyprus: A review and call for integrated policy. Water 2014, 6, 2898-2928. [CrossRef]

30. Hadjidemetriou, T. Lack of Water Resources and Agriculture; Council of Europe Publishing: The Hague, The Netherlands, 2000.

31. Nikolaou, G.; Neocleous, D.; Christophi, C.; Heracleous, T.; Markou, M. Irrigation Groundwater Quality Characteristics: A Case Study of Cyprus. Atmosphere 2020, 11, 302. [CrossRef]

32. Constantinidou, K.; Zittis, G.; Hadjinicolaou, P. Variations in the simulation of climate change impact indices due to different land surface schemes over the Mediterranean, Middle East and northern Africa. Atmosphere 2019, 10, 26. [CrossRef]

33. Lange, M.A. Impacts of climate change on the eastern Mediterranean and the Middle East and North Africa region and the water-energy nexus. Atmosphere 2019, 10, 455. [CrossRef]

34. Papadavid, G.; Neocleous, D.; Kountios, G.; Markou, M.; Michailidis, A.; Ragkos, A.; Hadjimitsis, D. Using SEBAL to Investigate How Variations in Climate Impact on Crop Evapotranspiration. J. Imaging 2017, 3, 30. [CrossRef]

35. Verdouw, C.; Wolfert, J.; Beers, G.; Sundmaeker, H.; Chatzikostas, G. Fostering business and software ecosystems for large-scale uptake of IoT in food and farming. In Proceedings of the PA17-The International Tri-Conference for Precision Agriculture in 2017, Hamilton, New Zealand, 16-18 October 2017.

36. Kalatzis, N.; Marianos, N.; Chatzipapadopoulos, F. IoT and data interoperability in agriculture: A case study on the gaiasense TM smart farming solution. In Proceedings of the 2019 Global IoT Summit (GIoTS), Aarhus, Denmark, 17-21 June 2019; pp. 1-6.

37. Marianos, N.; Kalatzis, N.; Sykas, D. Earth observation for smart farming and cap performance. In The Ever-Growing Use of Copernicus Across Europe's Regions; NEREUS, Ed.; European Commission: Brussels, Belgium, 2018.

38. Damos, P.; Savopoulou-Soultani, M. Temperature-driven models for insect development and vital thermal requirements. Psyche J. Entomol. 2012, 13. [CrossRef]

39. Leiminger, J.; Hausladen, H. Early blight control in potato using disease-orientated threshold values. Plant Dis. 2012, 96, 124-130. [CrossRef]

40. Escuredo, O.; Seijo-Rodríguez, A.; Rodríguez-Flores, M.S.; Seijo, M.C. Decision Support Systems for Detecting Aerial Potato Phytophthora infestans Sporangia in Northwestern Spain. Agron. J. 2019, 111, 354-361. [CrossRef]

41. Kantwa, S.; Shekhawat, K.; Tetarwal, J. Studies on physiological parameters of Alternaria alternata (Fr) keissler-The incitant of leaf blight of groundnut. Int. J. Plant Prot. 2015, 8, 359-363. [CrossRef]

42. Maheshwari, S.; Singh, D.; Singh, S. Effect of temperature and $\mathrm{pH}$ on growth and sporulation of Alternaria alternata causing Alternaria leaf spot of dolichos bean. Ann. Plant Prot. Sci. 2000, 8, 33-35.

43. Patakas, A. Abiotic stress-induced morphological and anatomical changes in plants. In Abiotic Stress Responses in Plants; Springer: Berlin/Heidelberg, Germany, 2012; pp. 21-39.

44. Karafyllidis, D.; Stavropoulos, N.; Georgakis, D. The effect of water stress on the yielding capacity of potato crops and subsequent performance of seed tubers. Potato Res. 1996, 39, 153-163. [CrossRef]

45. Allen, R.G.; Pereira, L.S.; Raes, D.; Smith, M. Crop evapotranspiration-Guidelines for computing crop water requirements-FAO Irrigation and drainage paper 56. Fao Rome 1998, 300, D05109.

46. Christou, A.; Dalias, P.; Neocleous, D. Spatial and temporal variations in evapotranspiration and net water requirements of typical Mediterranean crops on the island of Cyprus. J. Agric. Sci. 2017, 155, 1311-1323. [CrossRef]

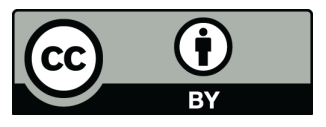

(C) 2020 by the authors. Licensee MDPI, Basel, Switzerland. This article is an open access article distributed under the terms and conditions of the Creative Commons Attribution (CC BY) license (http://creativecommons.org/licenses/by/4.0/). 